\title{
Formation and Subduction of North Pacific Tropical Water and Their Interannual Variability
}

\author{
SHOTA KATSURA AND EITAROU OKA \\ Atmosphere and Ocean Research Institute, The University of Tokyo, Kashiwa, Japan \\ Bo QIU \\ Department of Oceanography, University of Hawai'i at Mānoa, Honolulu, Hawaii \\ NIKLAS SCHNEIDER \\ Department of Oceanography, and International Pacific Research Center, University of Hawai' $i$ at Mānoa, \\ Honolulu, Hawaii
}

(Manuscript received 7 February 2013, in final form 25 August 2013)

\begin{abstract}
Formation and subduction of the North Pacific Tropical Water (NPTW), its interannual variability, and its associated mechanisms were investigated by using gridded Argo-profiling float data and various surface flux data in 2003-11. The NPTW has two formation sites in the center of the North Pacific subtropical gyre, corresponding to two regional sea surface salinity maxima. Mixed layer salinity variations in these two NPTW formation sites were found to be significantly different. While seasonal variation was prominent in the eastern formation site, interannual variation was dominant in the western site. The mixed layer salinity variation in the eastern site was controlled mainly by evaporation, precipitation, and entrainment of fresher water below the mixed layer and was closely related to the seasonal variation of the mixed layer depth. In the western site, the effect of entrainment is small due to a small vertical difference in salinity across the mixed layer base, and excess evaporation over precipitation that tended to be balanced by eddy diffusion, whose strength varied interannually in association with the Pacific decadal oscillation. After subduction, denser NPTW that formed in the eastern site dissipated quickly, while the lighter one that formed in the western site was advected westward as far as the Philippine Sea, transmitting the interannual variation of salinity away from its formation region.
\end{abstract}

\section{Introduction}

Salinity, along with temperature, is one of the most fundamental parameters in physical oceanography. In open oceans, its variations are mostly controlled by processes near the sea surface, particularly the surface freshwater flux, and its long-term changes reflect those in climate and the hydrological cycle. At the same time, salinity also determines water density and controls the ocean circulation, particularly at high latitudes where water temperature is low. Knowledge of salinity changes is important for a better understanding of climate and

Corresponding author address: Shota Katsura, Atmosphere and Ocean Research Institute, The University of Tokyo, 5-1-5 Kashiwanoha, Kashiwa, Chiba 277-8564 Japan.

E-mail: katsura@aori.u-tokyo.ac.jp the hydrological cycle, particularly because evaporation and precipitation, which occur mostly over the ocean (Schmitt 1995), have not been fully quantified.

Long-term salinity changes have been investigated by previous studies despite limited observations compared to those of temperature in the past. Wong et al. (1999) and Curry et al. (2003) contrasted the World Ocean Circulation Experiment Hydrographic Program (WHP) section data from around 1990 with the historical data from roughly $20 \mathrm{yr}$ earlier to indicate a freshening of intermediate waters characterized by a salinity minimum and salinification of tropical waters characterized by a salinity maximum in the Pacific, Indian, and Atlantic Oceans. Their results implied an intensification of the global hydrological cycle. A similar intensification of the salinity contrast between the subtropical and subarctic World Ocean has been presented by comparing 
Argo-profiling float data from after 2000 and historical measurements from before 2000 (Boyer et al. 2005; Hosoda et al. 2009; Roemmich and Gilson 2009; Durack and Wijffels 2010; Helm et al. 2010). Isopycnal freshening in the North Pacific permanent thermocline was also reported through comparison between the Argo and WHP data (Ren and Riser 2010).

In addition to the long-term changes, salinity variations on shorter time scales and their mechanisms have been explored by using data available at limited locations. At the station A Long-Term Oligotrophic Habitat Assessment (ALOHA) in the subtropical North Pacific, monthly shipboard observations during 1991-97 showed a freshening of upper thermocline water in association with a decadal increase in net freshwater flux (Lukas 2001). In the tropics, mooring observations under the Tropical Ocean and Global Atmosphere Coupled OceanAtmosphere Response Experiment (TOGA-COARE) and Prediction and Research Moored Array in the Tropical Atlantic (PIRATA) projects made it possible to investigate seasonal-to-interannual variations of salinity in the western equatorial Pacific (Sprintall and McPhaden 1994; Feng et al. 1998; Cronin and McPhaden 1998) and the tropical Atlantic (Segschneider et al. 2000; Foltz et al. 2004), respectively. Observations along repeat hydrographic sections and shipping tracks have also clarified broad-scale salinity variations and their zonal differences in each tropical ocean (Delcroix and Hénin 1991; Qiu and Joyce 1992; Dessier and Donguy 1994; Donguy and Meyers 1996; Delcroix et al. 1996; Delcroix and Picaut 1998).

In recent years, such exploration of salinity fields has become possible for most parts of the global upper ocean, thanks to the accumulation of Argo-profiling float data since 2000 (e.g., Roemmich et al. 2001). Ren and Riser (2009) used these data to estimate the mixed layer salinity (MLS) budget in the northeastern North Pacific where precipitation exceeds evaporation, and pointed out the importance of the entrainment of saltier water below the mixed layer for the increase of MLS from fall to winter. Similar analyses demonstrated that not only entrainment but also horizontal advection and sea ice processes are important for MLS variations in the Southern Ocean (Dong et al. 2009; Ren et al. 2011). Motivated further by the recent launches of the Soil Moisture Ocean Salinity (SMOS) satellite with Microwave Imaging Radiometer using Aperture Synthesis (MIRAS) by the European Space Agency (Kerr et al. 2001) and the Satelite de Aplicaciones Cientificas-D $(S A C-D)$ satellite with the Aquarius sensor by the National Aeronautics and Space Administration (NASA; Le Vine et al. 2007), upper-ocean salinity variability has attracted increasing attention, which led to the initiation of intensive studies such as the ongoing Salinity
Processes in the Upper Ocean Regional Study by NASA. Clarification of the seasonal and interannual variations of salinity and their mechanisms is not only important for understanding air-sea heat and freshwater exchanges but also for accurate estimation of long-term salinity changes.

In this study, we focus on the North Pacific Tropical Water (NPTW), a water mass characterized by a surface ocean salinity maximum. NPTW is formed at the sea surface in the subtropics where evaporation exceeds precipitation (Cannon 1966), and is then subducted and advected westward by the North Equatorial Current as a subsurface salinity maximum (Tsuchiya 1968; Qu et al. 1999). When NPTW reaches the Philippine coast ( $\mathrm{Li}$ and Wang 2012), it is split into two parts. One part is advected northward by the Kuroshio, while the other part flows southward in the Mindanao Current. The latter part partly passes the Celebes Sea (Fine et al. 1994) and then flows into the Indian Ocean (Ffield and Gordon 1992) or back to the North Pacific (Lukas et al. 1991; Kashino et al. 1996). When NPTW reaches the equatorial region carrying salinity or spiciness anomalies from the formation region in the subtropics, it can influence the sea surface temperature variability through the formation of a barrier layer (Lukas and Lindstrom 1991) and climate in the Pacific region ( $\mathrm{Gu}$ and Philander 1997; Schneider et al. 1999; Sasaki et al. 2010). NPTW carried northward by the Kuroshio can affect the salinity/spiciness distribution in the permanent pycnocline of the subtropical gyre through the formation of mode waters in the Kuroshio Extension region (Oka 2009; Oka et al. 2011; Oka and Qiu 2012).

Long-term variation of NPTW was investigated by Suga et al. (2000), who analyzed repeat hydrographic section data along $137^{\circ} \mathrm{E}$ during $1967-95$, which is located to the west (downstream) of the NPTW formation region. They demonstrated salinification of NPTW in association with the climate regime shift in the 1970s (Nitta and Yamada 1989; Trenberth 1990) that is characterized by a southward shift and intensification of the Aleutian low in winter. Specifically, the northern part of NPTW in the $137^{\circ} \mathrm{E}$ section increased both its salinity and thickness, while the southern part increased only its salinity. By using limited surface flux data, Suga et al. (2000) argued that the southern salinification is possibly due to the changes of evaporation over precipitation and Ekman salt convergence in the NPTW formation region, while the northern one may be due to the increase of the NPTW formation rate in the formation region. Because climatological streamfunction implies that the northern (southern) part of NPTW at $137^{\circ} \mathrm{E}$ is formed in the western (eastern) site of the formation region, the different pattern of NPTW change within the $137^{\circ} \mathrm{E}$ section in the 1970s suggests that the NPTW signals varied 


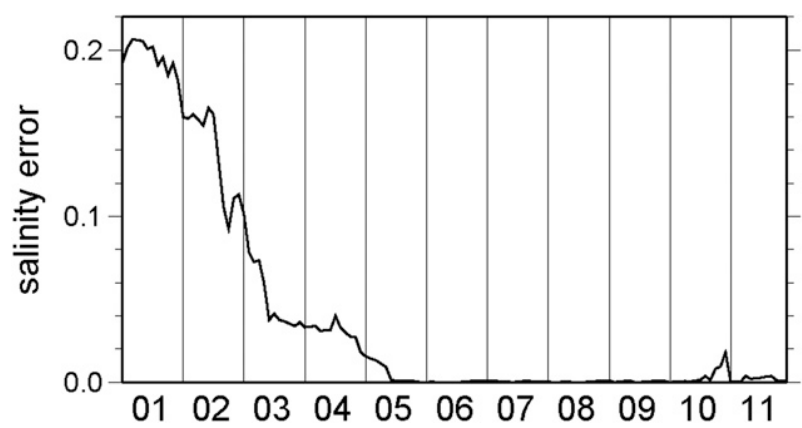

FIG. 1. Time series of the interpolation error in 10-dbar salinity of MOAA GPV, averaged in the subtropical North Pacific at $15^{\circ}-$ $30^{\circ} \mathrm{N}, 165^{\circ} \mathrm{E}-125^{\circ} \mathrm{W}$

between the western and eastern sites of their formation region.

In this study, we investigate seasonal and interannual variations of NPTW in the two sites of its formation region and their mechanisms using Argo data and the latest surface flux data. Also explored is how NPTW is subducted and advected to the downstream as the subsurface salinity maximum, transmitting salinity anomalies generated in the formation region. We believe that the results of this study are important for understanding not only air-sea interaction but also sea surface salinity (SSS) variations that are now continuously monitored by $S M O S / M I R A S$ and $S A C-D / A q u a r i u s$. The data and methods are described in section 2. Variations of NPTW in its formation region and after subduction as well as its mechanisms are examined in section 3 . The NPTW formation mechanism and its zonal difference between the western and eastern sites of the formation region are further discussed in section 4. A summary is given in section 5 .

\section{Data and methods}

\section{a. Data}

We used monthly mean temperature and salinity data based on an Argo-profiling float, moored buoy, and shipboard observations, named Grid Point Value of the Monthly Objective Analysis using the Argo data (MOAA GPV; Hosoda et al. 2008), in 2003-11. This dataset was made by optimally interpolating the observed temperature and salinity anomalies from the World Ocean Atlas 2001 climatology (Conkright et al. 2002 ) onto $1^{\circ} \times 1^{\circ}$ grid points at each standard depth. In this study, the temperature and salinity data between 10 and 2000 dbar at each grid point were vertically interpolated at an interval of 1 dbar using the Akima spline (Akima 1970). The analysis period is validated by the


FIG. 2. Distributions of (a) $S$ at 10-dbar depth and (b) $E-P$ (cm month $\left.{ }^{-1}\right)$, (c) $E\left(\mathrm{~cm} \mathrm{month}^{-1}\right)$, and (d) $P\left(\mathrm{~cm} \mathrm{month}^{-1}\right)$ at the sea surface in the North Pacific, averaged in 2003-11. Dashed contours in (a),(b) indicate $S=35.35$ and $E-P=9 \mathrm{~cm} \mathrm{month}^{-1}$, respectively. Gray shading in (b) denotes negative values. Four thick rectangles indicate the NW, NE, SW, and SE boxes.

interpolation error of MOAA GPV salinity in the subtropical North Pacific, which rapidly decreased after 2001 and stayed small after 2003 corresponding to the improved Argo float coverage (Fig. 1).

We also used reanalysis evaporation data from the objectively analyzed air-sea heat fluxes project (Yu and Weller 2007; Yu et al. 2008), precipitation from the Climate Prediction Center Merged Analysis of Precipitation (CMAP; Xie and Arkin 1996, 1997), and wind stress from the National Centers of Environmental Prediction (NCEP; Kistler et al. 2001), whose horizontal resolutions are $1^{\circ} \times 1^{\circ}, 2.5^{\circ} \times 2.5^{\circ}$, and $1.875^{\circ} \times \sim 2^{\circ}$, respectively. All of these surface forcing datasets were not available when Suga et al. (2000) conducted their analysis. Sea surface height data from the Archiving, Validation, and Interpretation of Satellite Oceanographic data (AVISO) on a $0.25^{\circ} \times 0.25^{\circ}$ grid were also used. These data for each month from 2003 through 2011 were linearly interpolated onto the same grid points as MOAA GPV, after averaging the daily data from NCEP and AVISO for each month. CMAP precipitation data in December 2011 

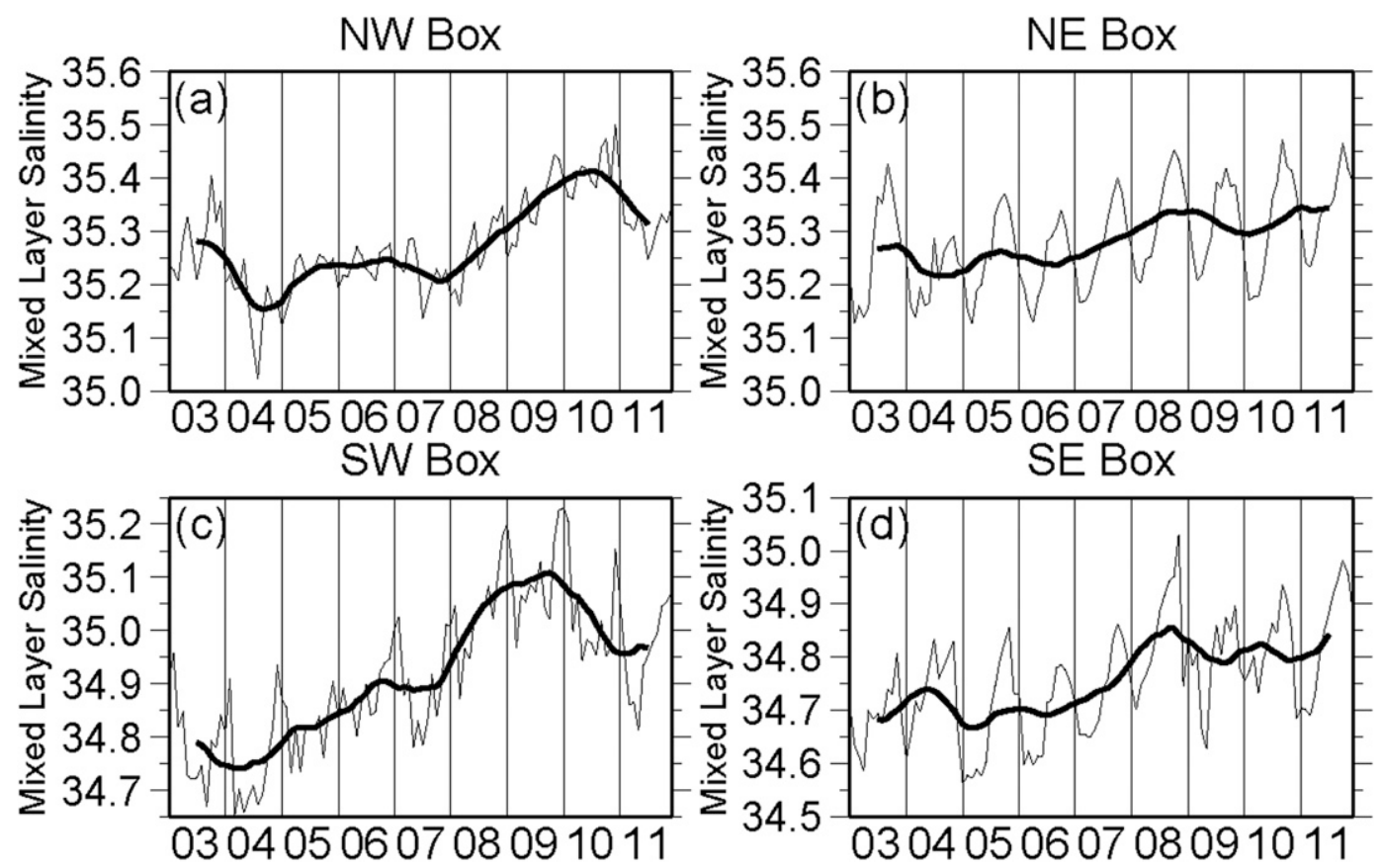

FIG. 3. Time series of MLS in the (a) NW, (b) NE, (c) SW, and (d) SE boxes in 2003-11 (thin curve). Thick curve indicates the 12-month moving average.

were not available at the time of this analysis, and we used the December average of 2003-10 as a substitute.

It should be mentioned that the analysis of this study was repeated using the evaporation data from NCEP and the precipitation data from NCEP and the Global Precipitation Climatology Project (Huffman et al. 1997; Adler et al. 2003). The results were not significantly different and are not shown.
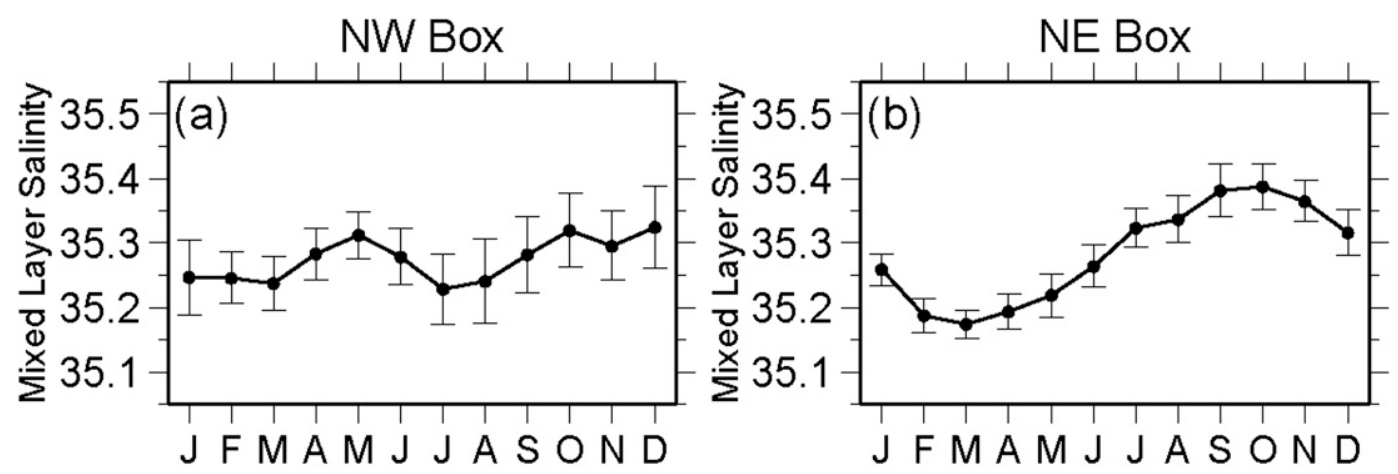

SW Box
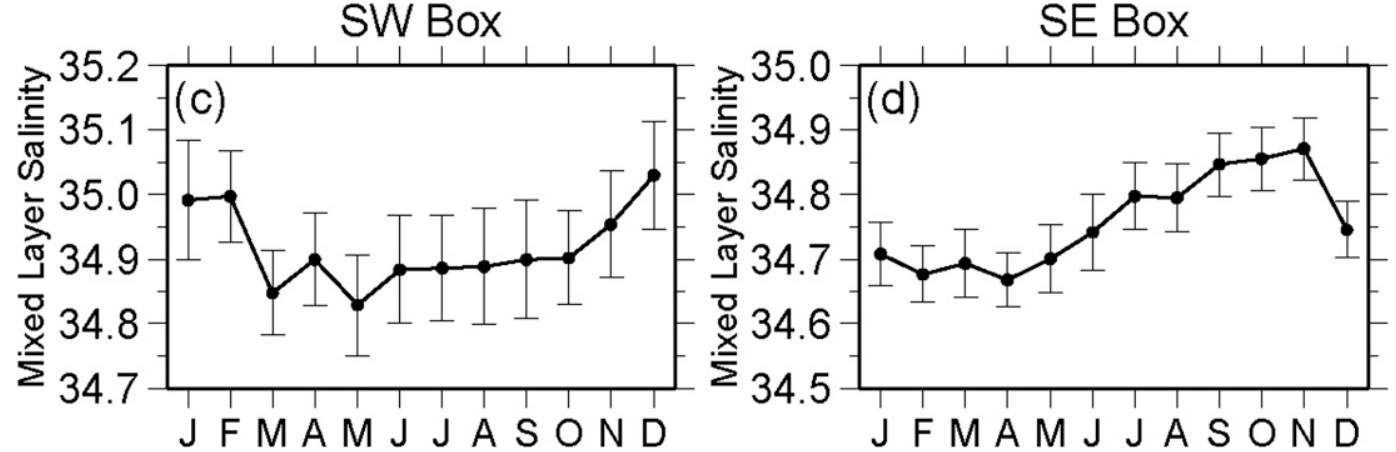

FIG. 4. Monthly average of MLS in 2003-11 in the (a) NW, (b) NE, (c) SW, and (d) SE boxes. Vertical bars indicate the $95 \%$ confidence interval. 
NE Box


FIG. 5. (a) Time series during 2003-11 of rate of change in MLS [lhs of Eq. (1); thick curve] and the sum of forcing terms [rhs of Eq. (1); thin curve] and (b) their monthly average in the NE box. (c) Time series during 2003-11 of each forcing term and (d) their monthly average in the NE box: $E$ term (red curve), $P$ term (blue curve), Ekman advection term (green curve), geostrophic advection term (orange curve), and entrainment term (purple curve). Vertical bars in (b) indicate the statistical error estimated from the $95 \%$ confidence interval of the forcing terms.

\section{b. Mixed layer salinity budget}

To investigate the mechanism of MLS variation, we used the budget equation of Ren and Riser (2009)

$$
\frac{\partial S}{\partial t}=\frac{(E-P) S}{h_{m}}-\mathbf{u}_{E} \cdot \nabla S-\mathbf{u}_{g} \cdot \nabla S-\frac{w_{e} \Delta S}{h_{m}}
$$

where $S$ is MLS, $t$ is time, $E$ is evaporation, $P$ is precipitation, $h_{m}$ is mixed layer depth (MLD), $\mathbf{u}_{E}$ is Ekman velocity, $\mathbf{u}_{g}$ is geostrophic velocity, $w_{e}$ is entrainment velocity through the mixed layer base, $\nabla$ is the horizontal differential operator, and $\Delta S$ is the salinity difference between the mixed layer base and 20 dbar below (former minus latter; e.g., Hayes et al. 1991). Here, MLD at each grid point was determined as the depth at which potential density $\sigma_{\theta}$ increases by $0.125 \mathrm{~kg} \mathrm{~m}^{-3}$ from the 10-dbar depth (Levitus 1982).

Ekman velocity was estimated from wind stress data as
NW Box

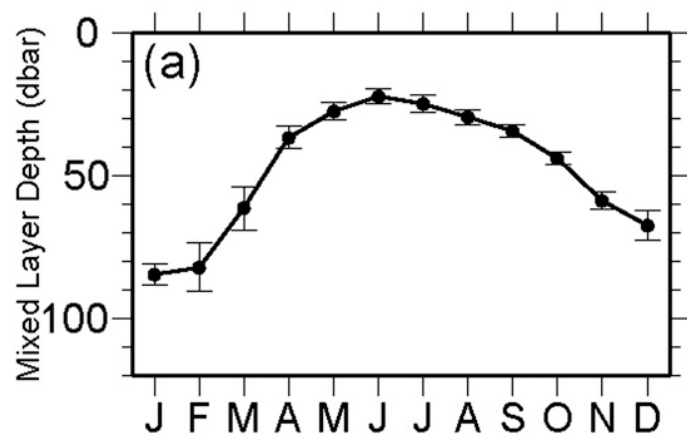

NE Box

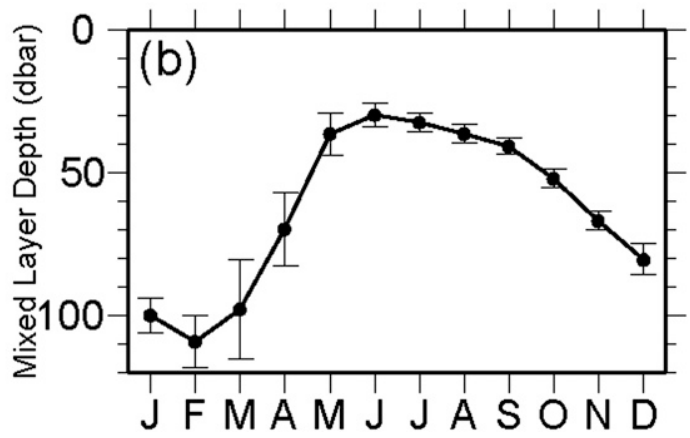

FIG. 6. Monthly average of MLD in 2003-11 in the (a) NW and (b) NE boxes. Vertical bars indicate the $95 \%$ confidence interval. 


\section{NW Box}
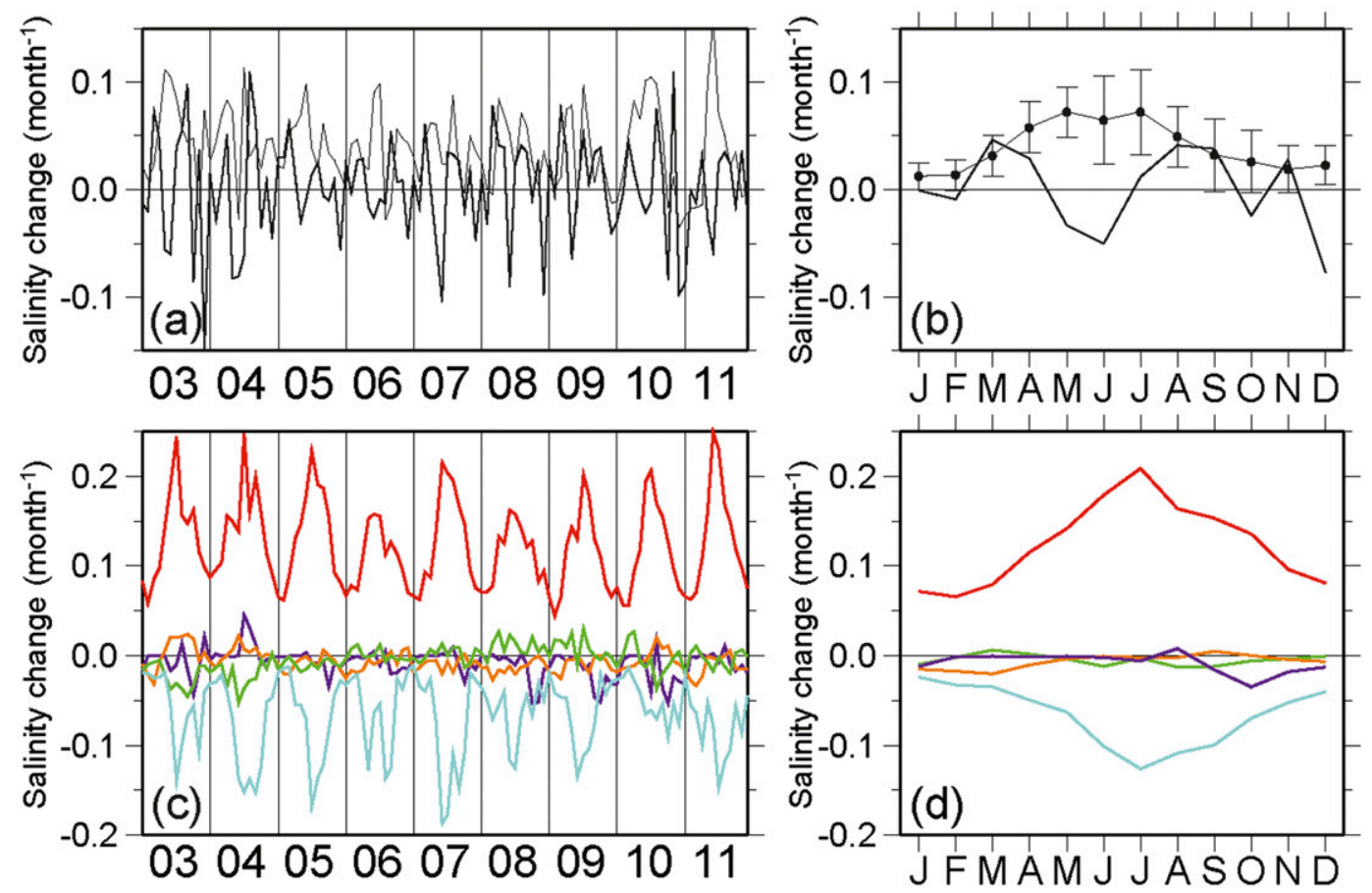

FIG. 7. As in Fig. 5, but for the NW box.

$$
\mathbf{u}_{E}=\frac{1}{\rho_{0} f h_{m}}\left(\tau^{y},-\tau^{x}\right)
$$

where $\tau^{x}$ and $\tau^{y}$ are zonal and meridional wind stresses (positive eastward and northward), $f$ is the Coriolis parameter, and $\rho_{0}$ is the reference density of seawater, taken to be $1025 \mathrm{~kg} \mathrm{~m}^{-3}$. Geostrophic velocity was calculated from sea surface height data assuming geostrophy.

Entrainment velocity was estimated as

$$
w_{e}=\left(\frac{\partial h_{m}}{\partial t}+\nabla \cdot h_{m} \mathbf{u}\right) H\left(\frac{\partial h_{m}}{\partial t}+\nabla \cdot h_{m} \mathbf{u}\right),
$$

where $\mathbf{u}$ is the sum of geostrophic and Ekman velocity, $H$ is the Heaviside step function, and

$$
H(x)=\left\{\begin{array}{ll}
1, & x \geq 0 \\
0, & x<0
\end{array} .\right.
$$

Here, we only consider the net positive entrainment velocity because detrainment does not affect the property of mixed layer.

\section{Result}

\section{a. Mixed layer salinity variation}

The mean SSS distribution in the North Pacific during 2003-11 shows a maximum exceeding 35.0 in the subtropics at $20^{\circ}-30^{\circ} \mathrm{N}, 155^{\circ} \mathrm{E}-135^{\circ} \mathrm{W}$ (Fig. 2a). NPTW is formed in this region as a winter surface mixed layer with high salinity (Cannon 1966; Suga et al. 2000; O'Connor et al. 2002). A further inspection of Fig. 2a reveals two separate SSS maxima exceeding 35.35 centered at $25^{\circ} \mathrm{N}$, $180^{\circ}$ and $27^{\circ} \mathrm{N}, 155^{\circ} \mathrm{W}$, respectively. The double SSS maxima are also seen in the surface salinity maps of previous works (e.g., Suga et al. 2000, 2004; O'Connor et al. 2002; Delcroix et al. 2005). The double maxima roughly correspond to those of evaporation minus precipitation $(E-P)$ located to their south/southeast (Fig. 2b). These double $E-P$ maxima have different evaporation and precipitation contributions; the western maximum is due to high evaporation, while the eastern one is due to low precipitation (Figs. $2 \mathrm{c}$ and $2 \mathrm{~d}$ ). This difference suggests that the salinity variations and their mechanisms may be distinct between the western and eastern sites of the NPTW formation region.

To investigate the regional difference in the NPTW variation around the formation region, four boxes were selected in association with the double SSS and $E-P$ maxima (Fig. 2): northwest (NW; $21^{\circ}-28^{\circ} \mathrm{N}, 165^{\circ} \mathrm{E}-172^{\circ} \mathrm{W}$ ), northeast (NE; $24^{\circ}-30^{\circ} \mathrm{N}, 165^{\circ}-140^{\circ} \mathrm{W}$ ), southwest (SW; $15^{\circ}-20^{\circ} \mathrm{N}, 165^{\circ} \mathrm{E}-170^{\circ} \mathrm{W}$ ), and southeast (SE; $16^{\circ}-24^{\circ} \mathrm{N}$, $150^{\circ}-125^{\circ} \mathrm{W}$ ). For each box, MLS was calculated for each month by averaging salinities at all $1^{\circ} \times 1^{\circ}$ grid points within the box from the sea surface to the MLD. 


\section{SE Box}
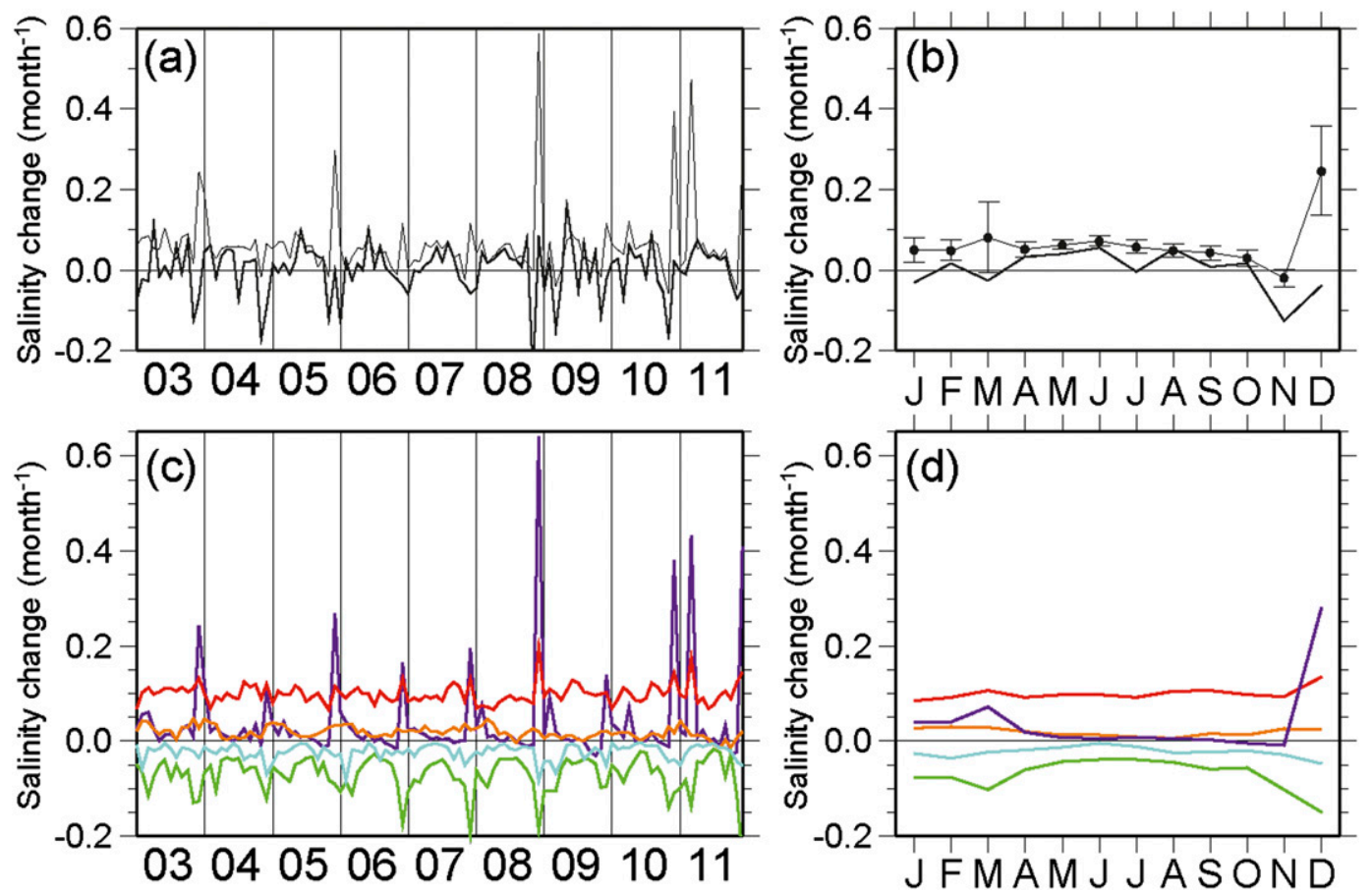

FIG. 8. As in Fig. 5, but for the SE box.

The obtained MLS variations were significantly different between the two SSS maximum boxes (Figs. 3a and $3 b$ ). Interannual variation was dominant in the NW box, while seasonal change was prevalent in the NE box. The MLS in the NE box was lowest in late winter around March and highest in late summer around SeptemberOctober almost every year (Figs. $3 b$ and $4 b$ ). The MLS in the NW box was not significantly different among months, although semiannual variation is discernible (Figs. 3a and 4a). Its interannual variation was characterized by a rapid increase of more than 0.2 in 2008-10.

MLS in the SW and SE boxes (Figs. 3c and 3d) showed similar variations to the $\mathrm{NW}$ and $\mathrm{NE}$ boxes, respectively. MLS in the SE box changed seasonally, being lowest around March and highest in November (Fig. 4d). In the SW box (Fig. 3c), interannual variation was dominant as in the NW box, and MLS increased rapidly in 2007-09, preceding that in the NW box by about one year. MLS in this box also changed seasonally, being highest in December and lowest in May on the seasonal average (Fig. 4c).

\section{b. Mixed layer salinity budget}

To investigate the mechanism of MLS variation in each box, variations of the terms in Eq. (1) were estimated. In the NE box, the rate of change in MLS on the left-hand side of Eq. (1) and the sum of the forcing terms on the right-hand side of Eq. (1) corresponded well to each other in terms of amplitude and phase, showing a high correlation both in the full time series (coefficient $R=$ 0.68 ; Fig. $5 \mathrm{a})$ and in the seasonal average $(R=0.85$; Fig. $5 b)$. The effect of Ekman and geostrophic advection was small due to the small horizontal salinity gradient in the SSS maximum area, and the variation of MLS was mainly forced by vertical processes, that is, evaporation, precipitation, and entrainment (Figs. 5c and 5d). In this box, evaporation almost always exceeded precipitation. The excess evaporation increased MLS during the warming period from March through September, when the mixed layer shoaled and then stayed shallow (Fig. 6b). On the other hand, during the cooling period from October through February when the mixed layer deepened, the effect of entrainment of underlying fresher water into the mixed layer exceeded that of the excess evaporation, decreasing MLS. Thus, MLS fluctuated in association with MLD, being highest (lowest) in September-October (March) when the mixed layer was shallow (deep), as demonstrated in Fig. 4b. Such an MLS variation and its budget contrast with those in the subarctic North Pacific (Ren and Riser 2009), where salinity increases with depth and, resultantly, MLS is highest (lowest) in March-April (September-October).

In the NW box, the rate of change in MLS showed semiannual variation, while the sum of forcing terms 


\section{SW Box}
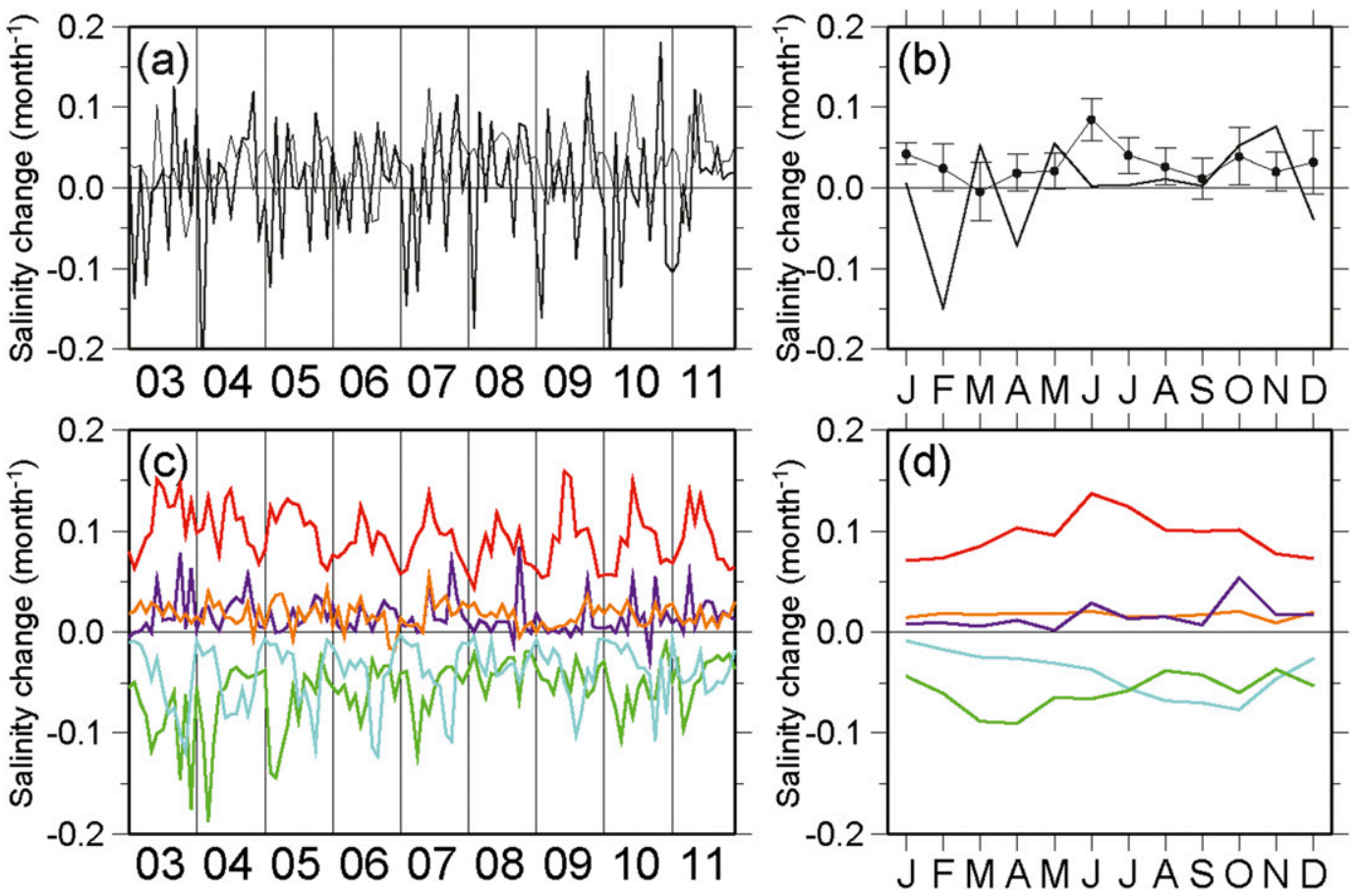

FIG. 9. As in Fig. 5, but for the SW box.

showed annual variation (Figs. 7a and 7b). As a result, the rate of change in MLS and the sum of the forcing terms were poorly correlated both on the full time series $(R=-0.02$; Fig. $7 \mathrm{a})$ and on the seasonal average $(R=$ -0.03 ; Fig. 7b). In this box, the effect of entrainment was much smaller than the NE box (Figs. 5c, 5d, 7c, and 7d). The MLD and its temporal change in this box were smaller than the NE box (Figs. 6a and 6b), as previously demonstrated (Delcroix et al. 2005), which makes both $w_{e}$ and $h_{m}$ in the entrainment term [Eq. (1)] smaller. The small entrainment was primarily due to a smaller $\Delta S$ in this box, which will be discussed in section 4 . Thus, the forcing terms in this box were dominated by evaporation and precipitation (Figs. 7c and 7d). Because evaporation was always higher than precipitation, the sum of forcing terms was always positive and the MLS budget did not close.

In the SE box, the sum of the forcing terms was almost always larger than the rate of change in MLS and had a large value in December (Figs. 8a and 8b), likely because of the underestimation of MLD in the southern part of the box using MOAA GPV data. Without the December values, the correlation between the two terms was moderately positive both on the full time series $(R=0.40$; Fig. $8 \mathrm{a})$ and on the seasonal average $(R=$ 0.69 ; Fig. $8 \mathrm{~b})$. The forcing terms are notably different from the NE box in two aspects. First, the Ekman term had a large contribution to decrease MLS (Figs. 8c and 8d), unlike the negligible contribution in the NE box (Figs. $5 \mathrm{c}$ and $5 \mathrm{~d}$ ). The large Ekman term is caused by a large northwestward gradient of MLS (Fig. 2a) and the strong northeasterly trade winds in this box; it transports salinity northward to the SSS maximum area, that is, the NPTW formation region. Second, the entrainment term worked to increase MLS, which was opposite to the NE box. This indicates the existence of saltier water below the mixed layer, which is NPTW subducted from the formation region. In the SW box, the rate of change in MLS and the sum of the forcing

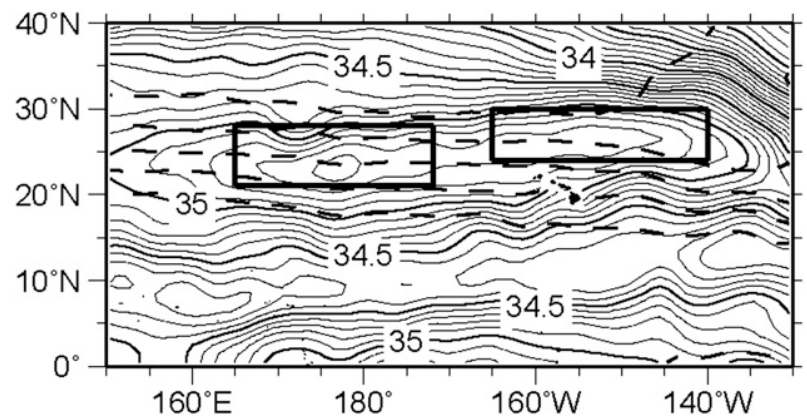

FIG. 10. Distribution of 10-dbar salinity (solid contours), averaged in January-March 2003-11. Dashed contours denote potential density of $23.0,23.5,24.0,24.5$, and $25.0 \mathrm{~kg} \mathrm{~m}^{-3}$ at 10 -dbar depth from the south. Two thick rectangles indicate the NW and NE boxes. 

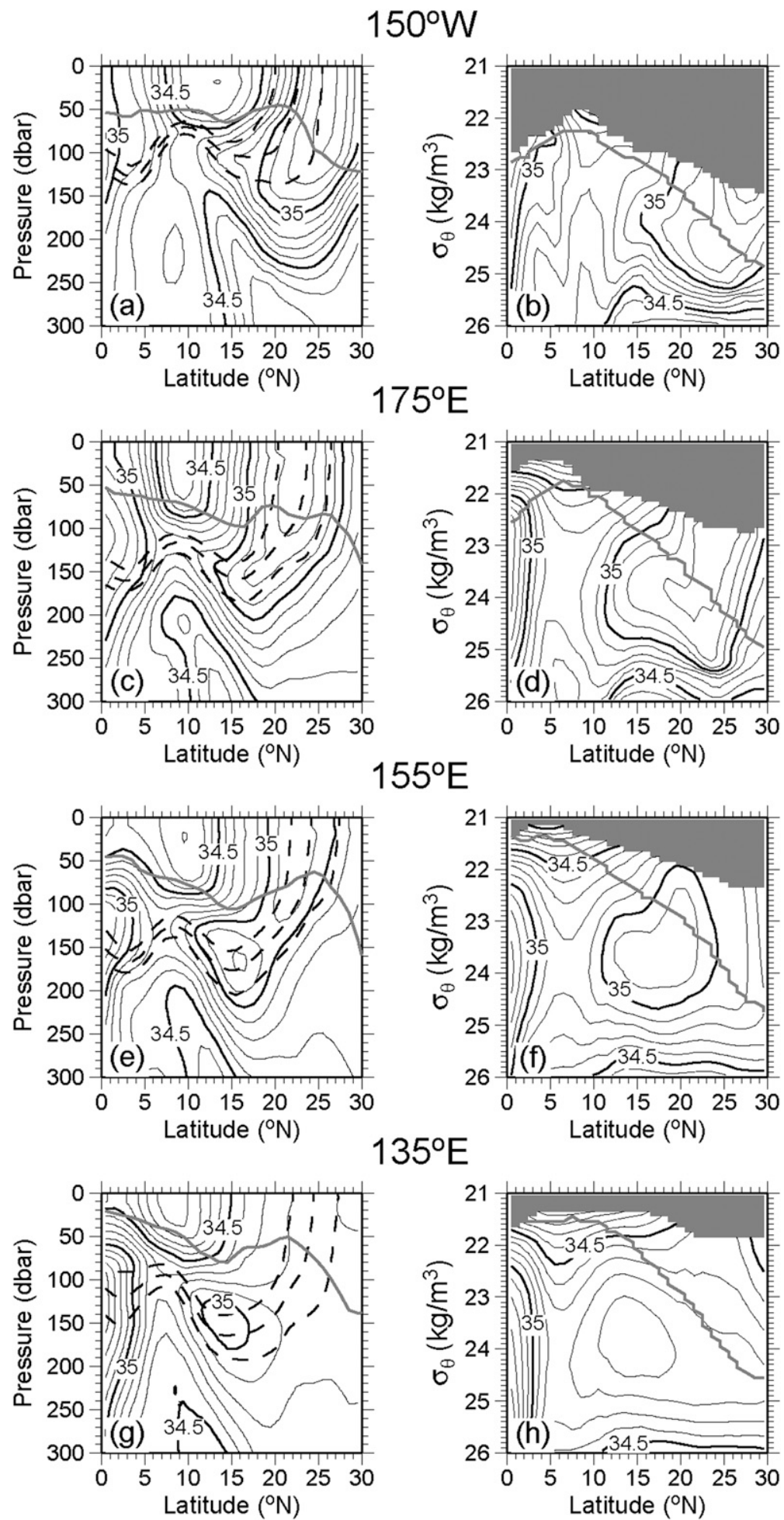

FIG. 11. Meridional section of salinity with respect to pressure, averaged in February $2003-11$ along (a) $150^{\circ} \mathrm{W}$, (c) $175^{\circ} \mathrm{E}$, (e) $155^{\circ} \mathrm{E}$, and (g) $135^{\circ} \mathrm{E}$ (black solid line). Dashed lines indicate isopycnals of $\sigma_{\theta}=23.5,24.0$, and $24.5 \mathrm{~kg} \mathrm{~m}^{-3}$. Gray solid line denotes the mixed layer base. Meridional section of salinity with respect to $\sigma_{\theta}$, averaged in August $2003-11$ along (b) $150^{\circ} \mathrm{W}$, (d) $175^{\circ} \mathrm{E}$, (f) $155^{\circ} \mathrm{E}$, and (h) $135^{\circ} \mathrm{E}$ (black line). Gray line indicates the outcrop surface in February. 


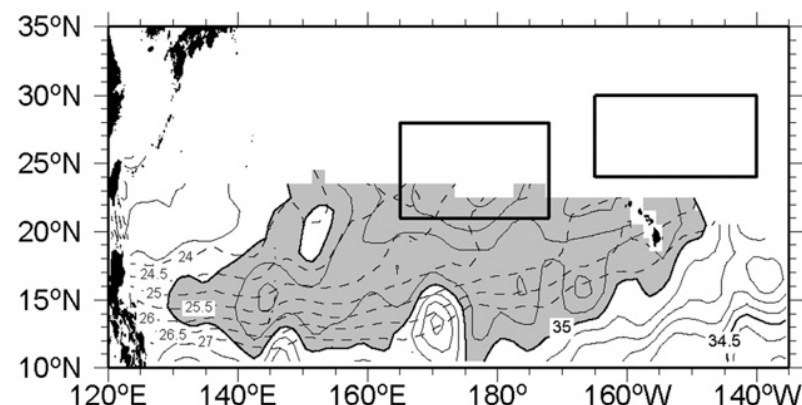

FIG. 12. Distribution of salinity (solid contours) and acceleration potential $\left(\mathrm{m}^{2} \mathrm{~s}^{-2}\right.$; dashed contours) on the $\sigma_{\theta}=24.0 \mathrm{~kg} \mathrm{~m}^{-3}$ isopycnal, averaged in March 2003-11. Gray shading indicates salinity higher than 35. Two thick rectangles indicate the NW and NE boxes.

terms did not correspond with each other (Figs. 9a and $9 \mathrm{~b}$ ), with a low correlation both on the full time series $(R=0.07$; Fig. $9 \mathrm{a})$ and on the seasonal average $(R=-0.06$; Fig. $9 \mathrm{~b})$, as in the NW box. The Ekman term was important for MLS variation (Figs. 9c and 9d) and the entrainment term was positive, as in the SE box.

\section{c. Subduction of NPTW}

Given the significantly different variations of MLS between the western and eastern sites of the NPTW formation region (Figs. 3a and 3b), it is natural to ask how NPTW formed in these sites is subducted and then transported westward by the North Equatorial Current to impact the downstream regions such as the one observed by Suga et al. (2000) at $137^{\circ}$ E. A winter sea surface density map shows that isopycnals of 24.0 and $24.5 \mathrm{~kg} \mathrm{~m}^{-3}$ traversed the center of the SSS maximum in the western and eastern sites of the NPTW formation region, respectively (Fig. 10). Consistently, at $150^{\circ} \mathrm{W}$ in the middle of the NE box, NPTW with $\sigma_{\theta} \sim 24.5 \mathrm{~kg} \mathrm{~m}^{-3}$ was subducted (Figs. 11a and 11b). Where $175^{\circ} \mathrm{E}$ crosses the center of the NW box, NPTW with $\sigma_{\theta}=\sim 24.0 \mathrm{~kg} \mathrm{~m}^{-3}$ was subducted; however, NPTW of $24.5 \mathrm{~kg} \mathrm{~m}^{-3}$, which is thought to be subducted from the NE box, no longer appeared as the salinity maximum at this longitude (Figs. 11c and 11d). NPTW subducted from east of Hawaii might be dissipated rapidly, as suggested in a numerical simulation (R. Furue 2012, personal communication). Farther west at $155^{\circ}$ and $135^{\circ} \mathrm{E}$, NPTW did not outcrop to the surface and became gradually lighter to the downstream centered at $\sigma_{\theta}=23.5-24.0 \mathrm{~kg} \mathrm{~m}^{-3}$ (Figs. 11e-h). In addition, the isopycnal salinity map on $\sigma_{\theta}=24.0 \mathrm{~kg} \mathrm{~m}^{-3}$ indicates that the high-salinity tongue departed from the NW box and extended southwestward along the streamlines (Fig. 12). Thus, NPTW observed as the subsurface

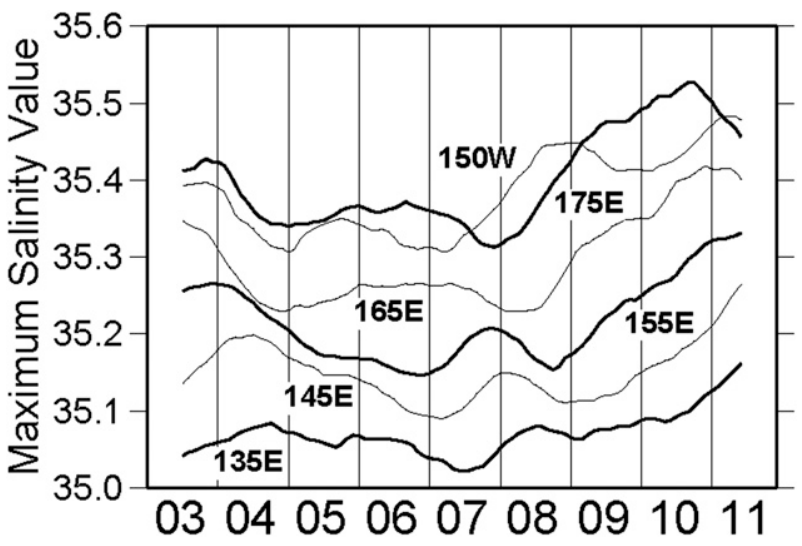

FIG. 13. Time series during 2003-11 of the 12-month moving average of the max salinity value at each longitude lying north of $7^{\circ} \mathrm{N}$ and below the mixed layer base.

salinity maximum to the west (downstream) of the formation region originates mainly in the western site of the formation region.

This is confirmed by comparing interannual variations of maximum salinity of NPTW at each longitude (Fig. 13). The interannual variations at $150^{\circ} \mathrm{W}$ and $175^{\circ} \mathrm{E}$ correspond to those of MLS in the NE and NW boxes (Figs. 3a and 3b), respectively. Farther west, the interannual variation in the NW box propagated westward, decreasing salinity values as a result of dissipation. For example, a salinity minimum observed around the end of 2007 at $175^{\circ} \mathrm{E}$ was seen in early 2008 at $165^{\circ} \mathrm{E}$, in late 2008 at $155^{\circ}$ and $145^{\circ} \mathrm{E}$, and in early 2009 at $135^{\circ} \mathrm{E}$; a salinity maximum observed mid-2006 at $175^{\circ} \mathrm{E}$ was seen in early 2007 at $165^{\circ} \mathrm{E}$, in late 2007 at $155^{\circ} \mathrm{E}$, in early 2008 at $145^{\circ} \mathrm{E}$, and in mid- 2008 at $135^{\circ} \mathrm{E}$. This westward propagation was also seen in a salinity anomaly distribution on the $\sigma_{\theta}=24.0 \mathrm{~kg} \mathrm{~m}^{-3}$ isopycnal (Fig. 14). A positive anomaly was generated around $160^{\circ} \mathrm{E}$ in 2003 and advected westward, reaching $135^{\circ} \mathrm{E}$ in mid-2005. A negative anomaly occurred around $165^{\circ} \mathrm{E}$ in early 2008 and arrived at $135^{\circ} \mathrm{E}$ in mid-2009. These propagations from the NW box to $135^{\circ} \mathrm{E}$ took about two years, being consistent with Fig. 13. This advection time is much shorter than that ( $\sim 5$ years) estimated from the World Ocean Atlas climatology (Bingham et al. 2002) and also than that ( $\sim 5$ years) observed on denser isopycnals of $\sigma_{\theta}=\sim 25.5 \mathrm{~kg} \mathrm{~m}^{-3}$ (Sasaki et al. 2010; Kolodziejczyk and Gaillard 2012). The westward advection speed estimated from the propagations in Figs. 13 and 14 is $\sim 10 \mathrm{~cm} \mathrm{~s}^{-1}$, which is comparable to the westward current speed of the North Equatorial Current on the isopycnal surface of $\sigma_{\theta}=24.0 \mathrm{~kg} \mathrm{~m}^{-3}$ estimated from MOAA GPV data, for example, one derived from the acceleration potential distribution in Fig. 12. 


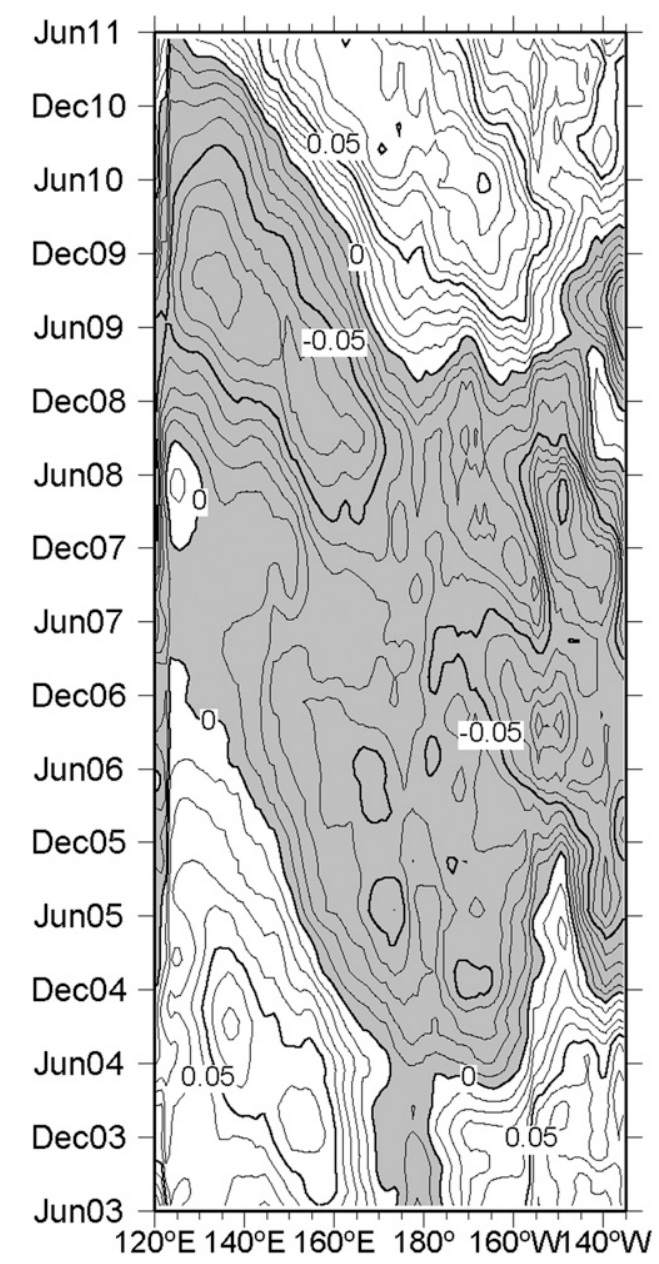

FIG. 14. Longitude-time plot of 12-month moving average of salinity anomaly on the $\sigma_{\theta}=24.0 \mathrm{~kg} \mathrm{~m}^{-3}$ isopycnal. The anomaly is relative to the 2003-11 average at each longitude and is averaged between $15^{\circ}$ and $20^{\circ} \mathrm{N}$. Gray shading denotes negative values.

\section{Discussion}

MLS showed a clear seasonal cycle in the NE box (Figs. 3b and $4 \mathrm{~b}$ ) and not in the NW box (Figs. 3a and 4a). In order for the seasonal cycle to exist, there should be both periods with positive and negative forcing during the course of a year. In the NE box, the effect of entrainment became large because of the increase of MLD and made the sum of the forcing terms negative from fall to winter (Fig. 5). In the NW box, on the other hand, the entrainment term did not become large even in fall-winter, and the sum of the forcing terms was always positive (Fig. 7). To clarify the reason for a small entrainment term in the NW box, we compared the vertical profile of salinity in these boxes (Fig. 15a). As these boxes are located in the NPTW formation region, salinity was at a maximum in the mixed layer and decreased with depth in the underlying layer in both boxes, with a larger vertical gradient in the NE box than in the NW box. The salinity difference between the mixed layer base and 20 dbar below [ $\Delta S$; Eq. (1)] in the NE box was about twice larger than in the NW box (Fig. 16). This suggests that the subduction of fresher water from the north into the layer below the mixed layer is strong (weak) in the NE (NW) box. Such subduction of fresher water must be important for the seasonal variation of NPTW in the eastern part of the formation region.

A similar zonal tendency in SSS variations has been obtained for the equatorial Pacific (Delcroix and Hénin 1991). That is, interannual variation was dominant in the western equatorial Pacific owing to the El NiñoSouthern Oscillation (ENSO)-related precipitation, while seasonal variation was prominent in the eastern equatorial Pacific. The seasonal cycle of SSS in the eastern equatorial region might be related to the entrainment of the South Pacific Tropical Water (Johnson and McPhaden 1999; Kessler 1999) and/or South Pacific Eastern Subtropical Mode Water (Wong and Johnson 2003; Sato and Suga 2009), which are subducted from the eastern South Pacific subtropical gyre and then advected to the equatorial region, in a similar manner that the subduction and entrainment of freshwater are important for the seasonal variation of the NPTW in the eastern part of its formation region.

In the SE box, the entrainment term increased the MLS (Fig. 8). This is because there is a subsurface salinity maximum layer, that is, NPTW subducted from the NE box (Fig. 15b). The mixed layer in the SE box takes in part of this NPTW, and is then advected back to the NE box by the Ekman flow, under the positive $E-P$ flux that continuously increases the MLS (Fig. 2b). Because the effect of northward Ekman advection is large in the SE box and small in the NE box (Figs. 5 and 8), salinity convergence occurs between two boxes, leading to the formation of the salinity maximum (i.e., NPTW) to the north of the $E-P$ maximum (Figs. 2a and $2 \mathrm{~b}$ ). Such a meridional overturning circulation of NPTW in the eastern regions is schematically illustrated in Fig. 17. In this circulation, the positive $E-P$ flux that increases the NPTW salinity in the mixed layer is balanced by dissipation and, more importantly, the freshwater flux from the lower, fresher layer in the formation region.

In the NW box, the salinity budget was not closed (section 3b). This means that the dissipation term, which is neglected in the MLS budget equation [Eq. (1)], has a considerable effect in this box. Actually, past observations based on the dispersion of surface drifters demonstrated that lateral diffusivity is about twice larger in the NW box than in the NE box (Zhurbas and Oh 2004). 

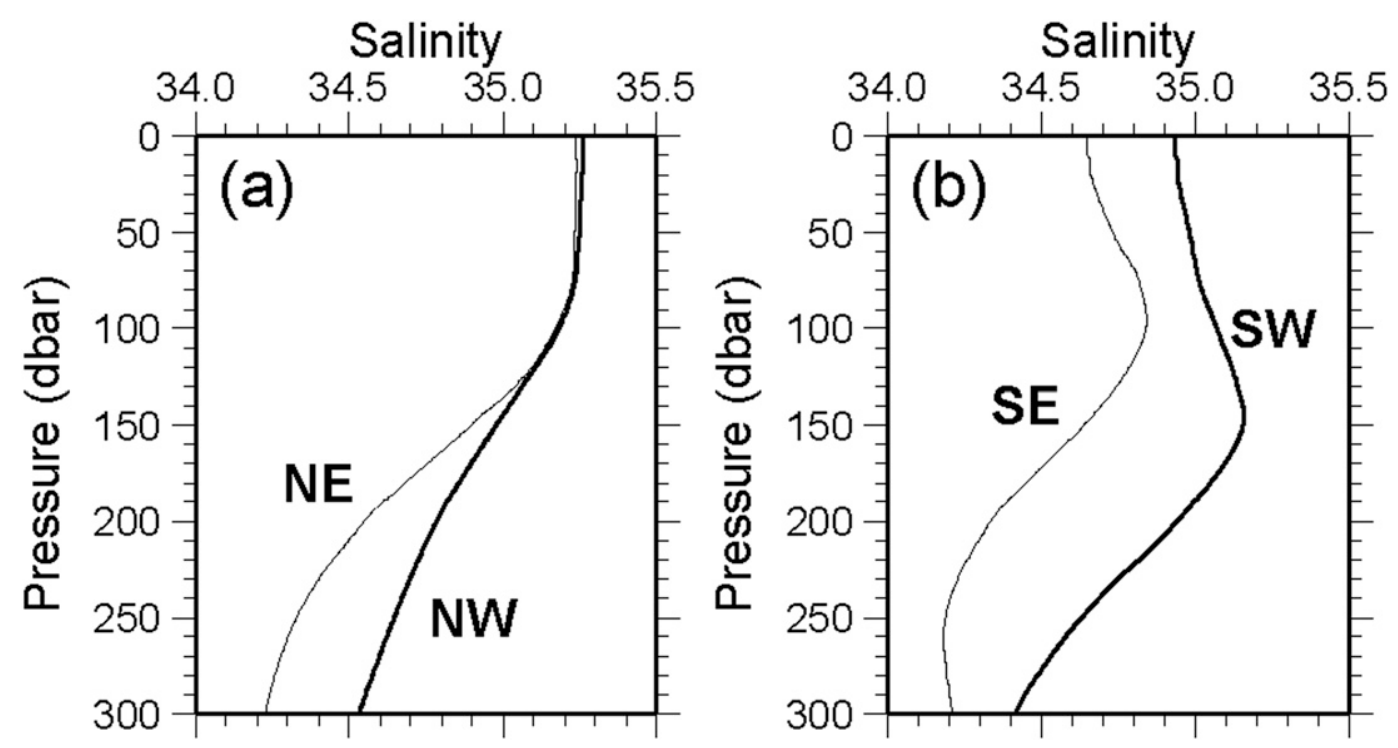

FIG. 15. Vertical profile of salinity averaged in the (a) NW and NE and (b) SW and SE boxes for January-March 2003-11.

If we assume that the lateral diffusivity is $1 \times 10^{4} \mathrm{~m}^{2} \mathrm{~s}^{-1}$ based on the map from Zhurbas and $\mathrm{Oh}$ and use the average $\nabla^{2} S$ of $5 \times 10^{-12} \mathrm{~m}^{-2}$ in the NW box (Fig. 2a), the decrease of MLS by diffusion is estimated to be $\sim 0.1$ month $^{-1}$. This matches in magnitude with the discrepancy between the rate of change in MLS and the sum of the forcing terms (Figs. 7a and 7b). Furthermore, Qiu and Chen (2013) analyzed satellite altimeter data during 1992-2012 and detected that eddy kinetic energy (EKE) in the subtropical North Pacific exhibits a larger variation in the NW box than in the NE box and was stronger in 2004 and 2007, when MLS in the NW box was relative low (Fig. 3a). Hence, we estimated the residual $A$ of Eq. (1) as

$$
\frac{\partial S}{\partial t}=\frac{(E-P) S}{h_{m}}-\mathbf{u}_{E} \cdot \nabla S-\mathbf{u}_{g} \cdot \nabla S-\frac{w_{e} \Delta S}{h_{m}}-A,
$$

and EKE, following Qiu and Chen (2013), as

$$
\mathrm{EKE}=\frac{1}{2}\left[\left(\frac{g}{f} \frac{\partial h^{\prime}}{\partial x}\right)^{2}+\left(\frac{g}{f} \frac{\partial h^{\prime}}{\partial y}\right)^{2}\right]
$$

where $x$ and $y$ are the zonal and meridional coordinates, $h^{\prime}$ is sea surface height anomaly, and $g$ is the gravity constant. The obtained EKE and $A$ showed similar interannual variation and are highly correlated with each other $(R=0.71$; Fig. $18 \mathrm{a})$. Thus, the interannual variation of MLS in the NW box was related to that of EKE. Moreover, EKE in this box also showed annual variation and was highest around May-June (Fig. 18b), suggesting that semiannual variation of MLS in the NW box (Fig. 4a) is due to the decrease of MLS around June by enhanced eddy diffusion.
NW Box

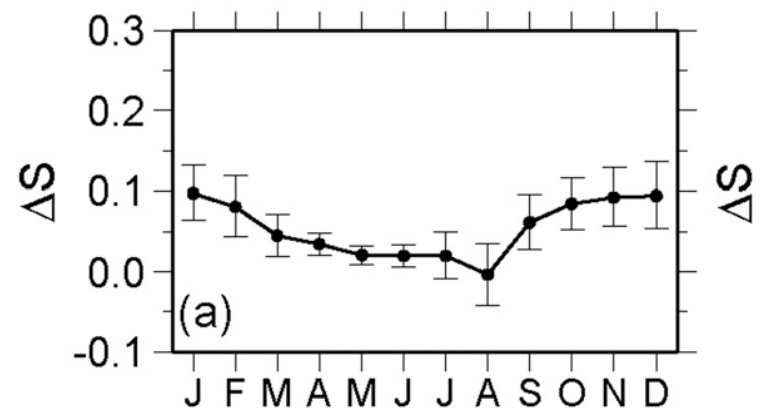



FIG. 16. Monthly average of $\Delta S$ in 2003-11 in the (a) NW and (b) NE boxes. Vertical bars indicate the $95 \%$ confidence interval. 


\section{Easterly Trade Winds}

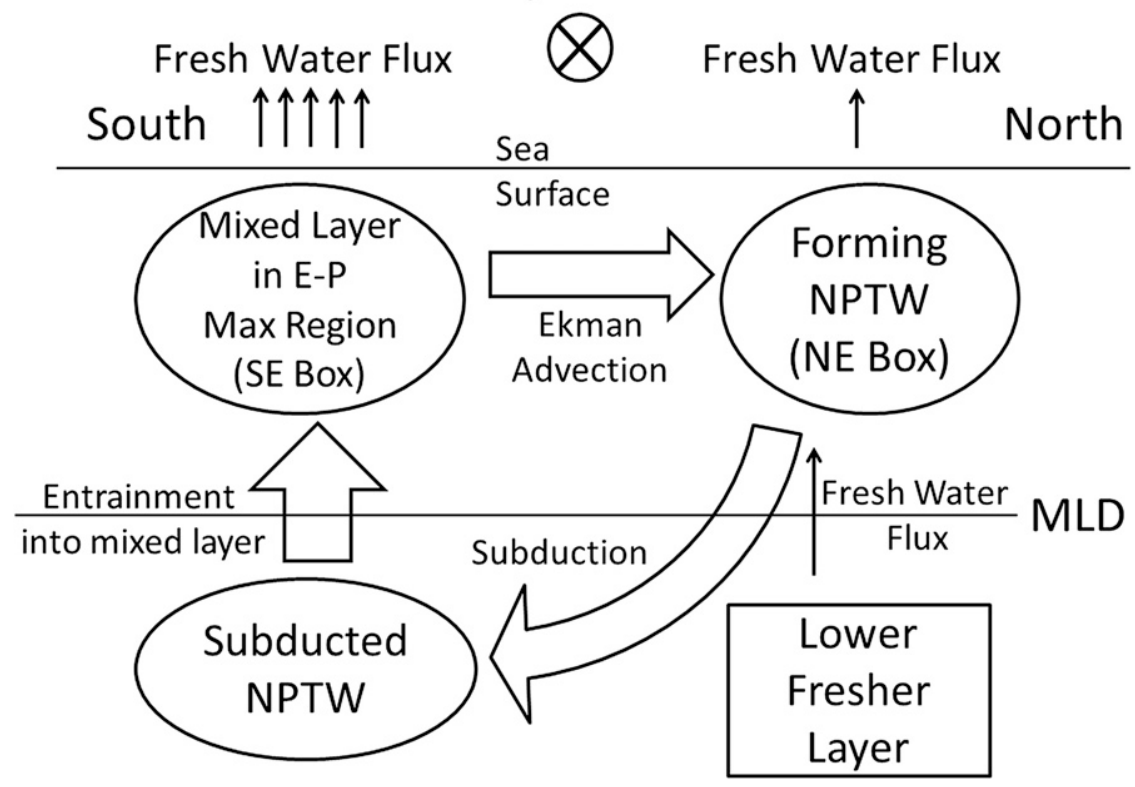

FIG. 17. Schematic diagram of the meridional overturning circulation of NPTW in the NE and SE boxes.

According to Qiu and Chen (2013), there is a positive correlation between EKE in the western subtropical North Pacific and the Pacific decadal oscillation (PDO; Mantua et al. 1997) index at least after 1992, and the latter led the former by one year. This suggests that the interannual variation of MLS in the NW box was also related to the PDO. To examine the relation for a sufficiently long period, we compared the variation of the salinity maximum value along the $137^{\circ} \mathrm{E}$ repeat hydrographic section of the Japan Meteorological Agency (Masuzawa 1967; Qiu and Joyce 1992; Suga et al. 2000) and that of the PDO index (available from http://www.data.kishou.go.jp/shindan/ b_1/pdo/winpdo.txt). The salinity maximum value at $137^{\circ} \mathrm{E}$ dropped several years after a period of positive PDO index, showing the strongest negative correlation with a time lag of 3 years $(R=-0.43$; Fig. 19). This time lag agrees with the sum of a 1-yr lag between the PDO index and the EKE (Qiu and Chen 2013) and a 2-yr period needed for the MLS variation in the NW box to propagate to $137^{\circ} \mathrm{E}$ (Fig. 13). Thus, the interannual variation of MLS in the NW box is likely to be controlled by the PDO-related eddy diffusion.

\section{Summary}

Formation and subduction of NPTW and their interannual variation have been investigated by using the MOAA GPV gridded Argo data and the various surface flux data in 2003-11. The MLS variations were significantly different between the western and eastern sites of the NPTW formation region. Interannual variation was dominant in the western site, while seasonal one was dominant in the eastern site.

The MLS variation in the eastern site was controlled mainly by evaporation, precipitation, and entrainment
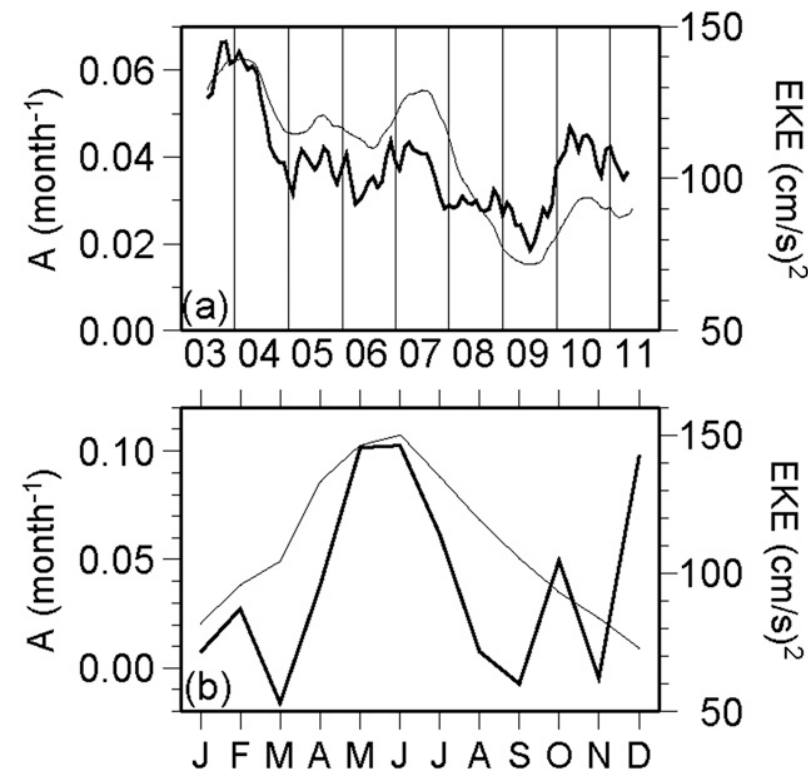

FIG. 18. Time series of (a) 12-month moving average and (b) monthly average in 2003-11 of $A$ (thick curve) and EKE (thin curve) in the NW box. 


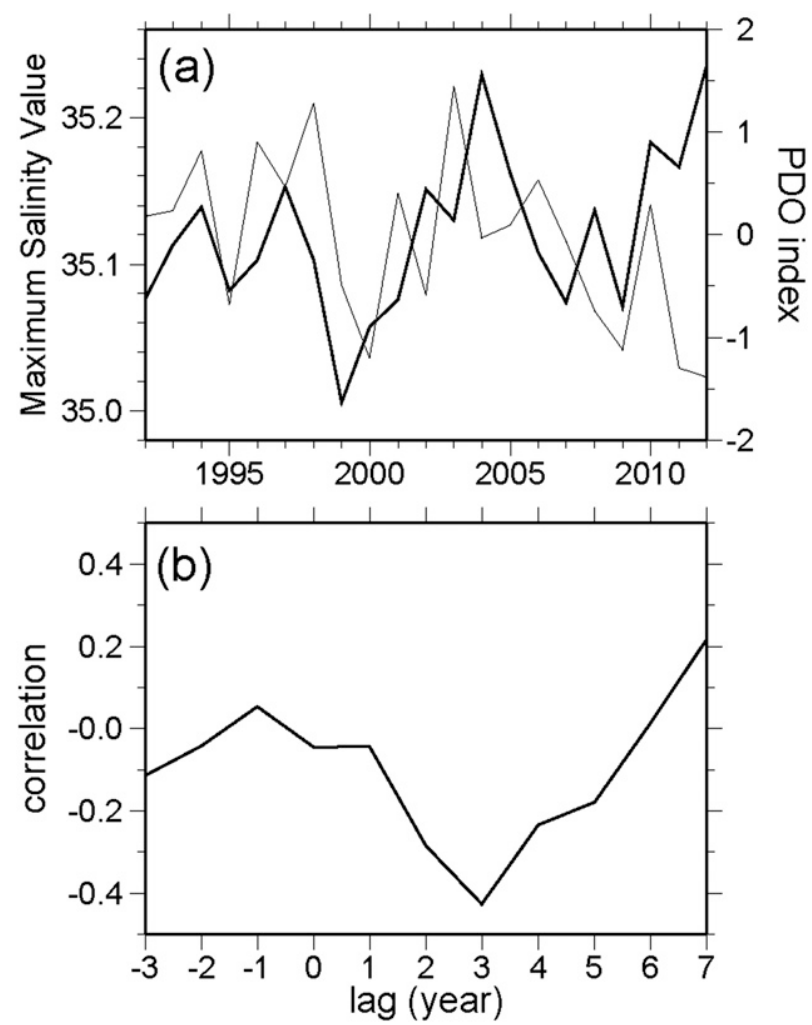

FIG. 19. (a) Time series of the winter max salinity value north of $7^{\circ} \mathrm{N}$ and below the mixed layer base in the $137^{\circ} \mathrm{E}$ repeat hydrographic section (thick curve) and the PDO index (thin curve). (b) Lag correlation between the salinity max value at $137^{\circ} \mathrm{E}$ and the PDO index. A positive lag indicates that the PDO index leads.

and was closely related to the mixed layer depth variation. Specifically, MLS increased from March to SeptemberOctober when the mixed layer shoaled and stayed shallow owing to the excess evaporation, while it decreased in the rest of year when the mixed layer deepened owing to the entrainment of fresher water. The existence of fresher water below the mixed layer, which is subducted from the north of the formation region, is important for the clear seasonal variation in the eastern site.

In the western site of the formation region where the effect of entrainment was small due to the small vertical difference in salinity across the mixed layer base, the forcing terms were governed by evaporation minus precipitation that was always positive throughout the year, and the salinity budget equation [Eq. (1)] is not closed. This imbalance is because we neglected the effect of dissipation in the budget equation. The residual term of the equation, defined as the difference between the rate of change in MLS and the sum of the forcing terms [Eq. (5)], was highly correlated with EKE in the western North Pacific which, in turn, was correlated with the PDO index. Thus, the MLS variation in the western site is likely to be controlled by evaporation, precipitation, and PDO-related eddy diffusion, at least after 1992.

From the western and eastern sites of the formation region, NPTW with $\sigma_{\theta}=24.0$ and $24.5 \mathrm{~kg} \mathrm{~m}^{-3}$ was subducted, respectively. Subsequently the NPTW formed at the eastern site was dissipated quickly, while that formed at the western site was advected westward, transmitting PDO-related salinity anomalies from the formation region to the Philippine Sea. It is an important future task to examine whether theses anomalies survive the intensive mixing in the Philippine Sea and how they are further advected and affect upper-ocean processes in the tropical Pacific and Kuroshio Extension regions.

This study has revealed the significant zonal differences in the MLS variation and the associated mechanism within the NPTW formation region. Similar zonal difference in the SSS variation was reported in the equatorial Pacific (Delcroix and Hénin 1991), although the interannual variation in the western subtropical North Pacific revealed here is related to the PDO, while that in the western equatorial Pacific is associated with ENSO (Delcroix and Hénin 1991). Such zonal and meridional differences suggest a necessity of further regional studies on the MLS variation. Specifically, we need to clarify the contribution of horizontal and vertical processes quantitatively by using Argo data and various surface flux data in each part of the global ocean. Such studies would be useful for understanding not only climate and hydrological cycle but also SSS variations monitored by $S M O S / M I R A S$ and $S A C-D /$ Aquarius.

Acknowledgments. The authors thank Ali Belmadani, Ryo Furue, Takuya Hasegawa, Shigeki Hosoda, Roger Lukas, Toshio Suga, and two anonymous reviewers for valuable comments. Part of this study was conducted during SK's one-month visit to the University of Hawaii at Manoa in October 2012 under the Overseas Internship Program for Outstanding Young Earth and Planetary Researchers provided by the Department of Earth and Planetary Science, The University of Tokyo. He appreciates Prof. T. Hibiya, who operates this program. SK is also supported by the Sasakawa Scientific Research Grant from the Japan Science Society. EO is supported by the Ministry of Education, Culture, Sports, Science and Technology, Japan (MEXT; Grant-in-Aid for Scientific Research on Innovative Areas under Grants 22106007 and 24121001).

\section{REFERENCES}

Adler, R. F., and Coauthors, 2003: The version-2 Global Precipitation Climatology Project (GPCP) monthly precipitation analysis (1979-present). J. Hydrometeor., 4, 1147-1167. 
Akima, H., 1970: A new method for interpolation and smooth curve fitting based on local procedures. J. Assoc. Comput. Mech., 17, 589-602.

Bingham, F. M., T. Suga, and K. Hanawa, 2002: Origin of waters observed along $137^{\circ}$ E. J. Geophys. Res., 107 (C7), doi:10.1029/ 2000JC000722.

Boyer, T. P., J. I. Antonov, S. Levitus, and R. Locarnini, 2005: Linear trends of salinity for the world ocean, 1955-1998. Geophys. Res. Lett., 32, L01604, doi:10.1029/2004GL021791.

Cannon, G. A., 1966: Tropical waters in the western Pacific Ocean, August-September 1957. Deep-Sea Res., 13, 1139-1148.

Conkright, M. E., R. A. Locarnini, H. E. Garcia, T. D. O'Brien, T. P. Boyer, C. Stephens, and J. I. Antonov, 2002: World Ocean Atlas 2001: Objective Analyses, Data Statistics and Figures. National Oceanographic Data Center, CD-ROM Documentation, $17 \mathrm{pp}$.

Cronin, M. F., and M. J. McPhaden, 1998: Upper ocean salinity balance in the western equatorial Pacific. J. Geophys. Res., 103, 27 567-27 587.

Curry, R., B. Dickson, and I. Yashayaev, 2003: A change in the freshwater balance of the Atlantic Ocean over the past four decades. Nature, 426, 826-829.

Delcroix, T., and C. Hénin, 1991: Seasonal and interannual variations of sea surface salinity in the tropical Pacific Ocean. J. Geophys. Res., 96, $22135-22150$.

—_, and J. Picaut, 1998: Zonal displacement of the western equatorial Pacific fresh pool. J. Geophys. Res., 103, 10871098.

— C. Henin, V. Porte, and P. Arkin, 1996: Precipitation and sea surface salinity in the tropical Pacific Ocean. Deep-Sea Res., 43, 1123-1141.

— M. J. McPhaden, A. Dessier, and Y. Gouriou, 2005: Time and space scales for sea surface salinity in the tropical oceans. Deep-Sea Res. I, 52, 787-813.

Dessier, A., and J. R. Donguy, 1994: The sea surface salinity in the tropical Atlantic between $10^{\circ} \mathrm{S}$ and $30^{\circ} \mathrm{N}$-Seasonal and interannual variations (1977-1989). Deep-Sea Res., 41, 81-100.

Dong, S., S. L. Garzoli, and M. Baringer, 2009: An assessment of the seasonal mixed layer salinity budget in the Southern Ocean. J. Geophys. Res., 114, C12001, doi:10.1029/2008JC005258.

Donguy, J. R., and G. Meyers, 1996: Seasonal variations of sea surface salinity and temperature in the tropical Indian Ocean. Deep-Sea Res., 43, 117-138.

Durack, P. J., and S. E. Wijffels, 2010: Fifty-year trends in global ocean salinities and their relationship to broad-scale warming. J. Climate, 23, 4342-4362.

Feng, M., P. Hacker, and R. Lukas, 1998: Upper ocean heat and salt balances in response to a westerly wind burst in the western equatorial Pacific during TOGA COARE. J. Geophys. Res., 103, 10289-10311.

Ffield, A., and A. L. Gordon, 1992: Vertical mixing in the Indonesian thermocline. J. Phys. Oceanogr., 22, 184-195.

Fine, R. A., R. Lukas, F. M. Bingham, M. J. Warner, and R. H. Gammon, 1994: The western equatorial Pacific: A water mass crossroads. J. Geophys. Res., 99, 25063-25080.

Foltz, G. R., S. A. Grodsky, J. A. Carton, and M. J. McPhaden, 2004: Seasonal salt budget of the northwestern tropical Atlantic Ocean along $38^{\circ}$ W. J. Geophys. Res., 109, C03052, doi:10.1029/ 2003JC002111.

Gu, D. F., and S. G. F. Philander, 1997: Interdecadal climate variability that depends on exchanges between the tropics and extratropics. Science, 275, 805-807.
Hayes, S. P., P. Chang, and M. J. McPhaden, 1991: Variability of the sea surface temperature in the eastern equatorial Pacific during 1986-1988. J. Geophys. Res., 96, 10 553-10566.

Helm, K. P., N. L. Bindoff, and J. A. Church, 2010: Changes in the global hydrological cycle inferred from ocean salinity. Geophys. Res. Lett., 37, L18701, doi:10.1029/2010GL044222.

Hosoda, S., T. Ohira, and T. Nakamura, 2008: A monthly mean dataset of global oceanic temperature and salinity derived from Argo float observations. JAMSTEC Rep. Res. Dev., 8, 47-59.

_- T. Suga, N. Shikama, and K. Mizuno, 2009: Global surface layer salinity change detected by Argo and its implication for hydrological cycle intensification. J. Oceanogr., 65, 579-586.

Huffman, G. J., and Coauthors, 1997: The Global Precipitation Climatology Project (GPCP) combined precipitation dataset. Bull. Amer. Meteor. Soc., 78, 5-20.

Johnson, G. C., and M. J. McPhaden, 1999: Interior pycnocline low from the subtropical to the equatorial Pacific Ocean. J. Phys. Oceanogr., 29, 3073-3089.

Kashino, Y., M. Aoyama, T. Kawano, N. Hendiarti Syaefudi, Y. Anantasena, K. Muneyama, and H. Watanabe, 1996: The water masses between Mindanao and New Guinea. J. Geophys. Res., 101, 12391-12400.

Kerr, Y. H., P. Waldteufel, J.-P. Wigneron, J.-M. Martinuzzi, J. Font, and M. Berger, 2001: Soil moisture retrieval from space: The Soil Moisture and Ocean Salinity (SMOS) mission. IEEE Trans. Geosci. Remote Sens., 39, 1729-1735.

Kessler, W. S., 1999: Interannual variability of the subsurface high salinity tongue south of the equator at $165^{\circ}$ E. J. Phys. Oceanogr., 29, 2038-2049.

Kistler, R., and Coauthors, 2001: The NCEP-NCAR 50-Year Reanalysis: Monthly means CD-ROM and documentation. Bull. Amer. Meteor. Soc., 82, 247-267.

Kolodziejczyk, N., and F. Gaillard, 2012: Observation of spiciness interannual variability in the Pacific pycnocline. J. Geophys. Res., 117, C12018, doi:10.1029/2012JC008365.

Le Vine, D. M., G. S. E. Lagerloef, F. R. Colomb, S. H. Yueh, and F. A. Pellerano, 2007: Aquarius: An instrument to monitor sea surface salinity from space. IEEE Trans. Geosci. Remote Sens., 45, 2040-2050.

Levitus, S., 1982: Climatological Atlas of the World Ocean. NOAA Prof. Paper 13, 173 pp. and 17 microfiche.

Li, Y., and F. Wang, 2012: Spreading and salinity change of North Pacific tropical water in the Philippine Sea. J. Oceanogr., 68, $439-452$.

Lukas, R., 2001: Freshening of the upper thermocline in the North Pacific subtropical gyre associated with decadal changes of rainfall. Geophys. Res. Lett., 28, 3485-3488.

_ - and E. Lindstrom, 1991: The mixed layer in the western equatorial Pacific Ocean. J. Geophys. Res., 96, 3343-3357.

_ E. Firing, P. Hacker, P. L. Richardson, C. A. Collins, R. Fine, and R. Gammon, 1991: Observations of the Mindanao Current during the western equatorial Pacific Ocean circulation study. J. Geophys. Res., 96, 7089-7104.

Mantua, N. J., S. R. Hare, Y. Zhang, J. M. Wallace, and R. C. Francis, 1997: A Pacific interdecadal climate oscillation with impacts on salmon production. Bull. Amer. Meteor. Soc., 78, 1069-1079.

Masuzawa, J., 1967: An oceanographic section from Japan to New Guinea at $137^{\circ} \mathrm{E}$ in January 1967. Oceanogr. Mag., 19, 95-118.

Nitta, T., and S. Yamada, 1989: Recent warming of tropical sea surface temperature and its relationship to the Northern Hemisphere circulation. J. Meteor. Soc. Japan, 67, 375-382. 
O'Connor, B. M., R. A. Fine, K. A. Maillet, and D. B. Olson, 2002: Formation rates of subtropical underwater in the Pacific Ocean. Deep-Sea Res., 49, 1571-1590.

Oka, E., 2009: Seasonal and interannual variation of North $\mathrm{Pa}-$ cific Subtropical Mode Water in 2003-2006. J. Oceanogr., 65, 151-164.

— , and B. Qiu, 2012: Progress of North Pacific mode water research in the past decade. J. Oceanogr., 68, 5-20.

- , S. Kouketsu, K. Toyama, K. Uehara, T. Kobayashi, S. Hosoda, and T. Suga, 2011: Formation and subduction of Central Mode Water Based on profiling float data, 2003-08. J. Phys. Oceanogr., 41, 113-129.

Qiu, B., and S. Chen, 2013: Concurrent decadal mesoscale eddy modulations in the western North Pacific subtropical gyre. J. Phys. Oceanogr., 42, 344-358.

- , and T. M. Joyce, 1992: Interannual variability in the mid- and low-latitude western North Pacific. J. Phys. Oceanogr., 22, 1062-1079.

Qu, T., H. Mitsudera, and T. Yamagata, 1999: A climatology of the circulation and water mass distribution near the Philippine Coast. J. Phys. Oceanogr., 29, 1488-1505.

Ren, L., and S. C. Riser, 2009: Seasonal salt budget in the northeast Pacific Ocean. J. Geophys. Res., 114, C12004, doi:10.1029/ $2009 \mathrm{JC} 005307$.

— , and — 2010: Observations of decadal time scale salinity changes in the subtropical thermocline of the North Pacific Ocean. Deep-Sea Res. II, 57, 1161-1170.

_ K. K. Speer, and E. P. Chassignet, 2011: The mixed layer salinity budget and sea ice in the Southern Ocean. J. Geophys. Res., 116, C08031, doi:10.1029/2010JC006634.

Roemmich, D., and J. Gilson, 2009: The 2004-2008 mean and annual cycle of temperature, salinity, and steric height in the global ocean from the Argo Program. Prog. Oceanogr., 82, 81-100.

_ - and Coauthors, 2001: Argo: The global array of profiling floats. Observing the Oceans in the 21st Century, C. J. Koblinsky and N. R. Smith, Eds., GODAE Project Office, Bureau of Meteorology, 248-258.

Sasaki, Y. N., N. Schneider, N. Maximenko, and K. Lebedev, 2010: Observational evidence for propagation of decadal spiciness anomalies in the North Pacific. Geophys. Res. Lett., 37, L07708, doi:10.1029/2010GL042716.

Sato, K., and T. Suga, 2009: Structure and modification of the South Pacific Eastern Subtropical Mode Water. J. Phys. Oceanogr., 39, 1700-1714.

Schmitt, R. W., 1995: The ocean component of the global water cycle. Rev. Geophys., 33 (S1), 1395-1410.
Schneider, N., A. J. Miller, M. A. Alexander, and C. Deser, 1999: Subduction of decadal North Pacific temperature anomalies: Observations and dynamics. J. Phys. Oceanogr., 29, 1056-1070.

Segschneider, J., M. Balmaseda, and D. L. T. Anderson, 2000: Anomalous temperature and salinity variations in the tropical Atlantic: Possible causes and implications for the use of altimeter data. Geophys. Res. Lett., 27, 2281-2284.

Sprintall, J., and M. J. McPhaden, 1994: Surface layer variations observed in multiyear time series measurements from the western equatorial Pacific. J. Geophys. Res., 99, 963-979.

Suga, T., A. Kato, and K. Hanawa, 2000: North Pacific Tropical Water: Its climatology and temporal changes associated with the climate regime shift in the 1970s. Prog. Oceanogr., 47, 223 256.

—, K. Motoki, Y. Aoki, and M. A. Macdonald, 2004: The North Pacific climatology of winter mixed layer and mode waters. J. Phys. Oceanogr., 34, 3-22.

Trenberth, K. E., 1990: Recent observed interdecadal climate changes in the Northern Hemisphere. Bull. Amer. Meteor. Soc., 71, 988-993.

Tsuchiya, M., 1968: Upper waters of the intertropical Pacific Ocean. Johns Hopkins Oceanographic Studies, No. 4, Johns Hopkins University Press, $50 \mathrm{pp}$.

Wong, A. P. S., and G. C. Johnson, 2003: South Pacific Eastern Subtropical Mode Water. J. Phys. Oceanogr., 33, 1493-1509.

_ , N. L. Bindoff, and J. A. Church, 1999: Large-scale freshening of intermediate waters in the Pacific and Indian Oceans. $\mathrm{Na}$ ture, 400, 440-443.

Xie, P., and P. A. Arkin, 1996: Analyses of global monthly precipitation using gauge observations, satellite estimates, and numerical model predictions. J. Climate, 9, 840-858.

_ and —, 1997: A 17-year monthly analysis based on gauge observations, satellite estimates and numerical model outputs. Bull. Amer. Meteor. Soc., 78, 2539-2558.

Yu, L., and R. A. Weller, 2007: Objectively analyzed air-sea heat fluxes (OAFlux) for the global ocean. Bull. Amer. Meteor. Soc., 88, 527-539.

- X. Jin, and R. Weller, 2008: Multidecade global flux datasets from the objectively analyzed air-sea fluxes (OAFlux) project: Latent and sensible heat fluxes, ocean evaporation, and related surface meteorological variables. OAFlux Project Tech. Rep. OA-2008-01, 64 pp.

Zhurbas, V., and I. S. Oh, 2004: Drifter-derived maps of lateral diffusivity in the Pacific and Atlantic Oceans in relation to surface circulation patterns. J. Geophys. Res., 109, C05015, doi:10.1029/2003JC002241. 